\title{
Design of semi-Z source inverter topology with reduced number switches for four quadrant control of direct current motor
}

\author{
Waseah Anjum, Sudeekshya Panda, Palanisamy Ramasamy \\ Department of Electrical and Electronics Engineering, SRM Institute of Science and Technology, Kattankulathur, Tamil Nadu, India
}

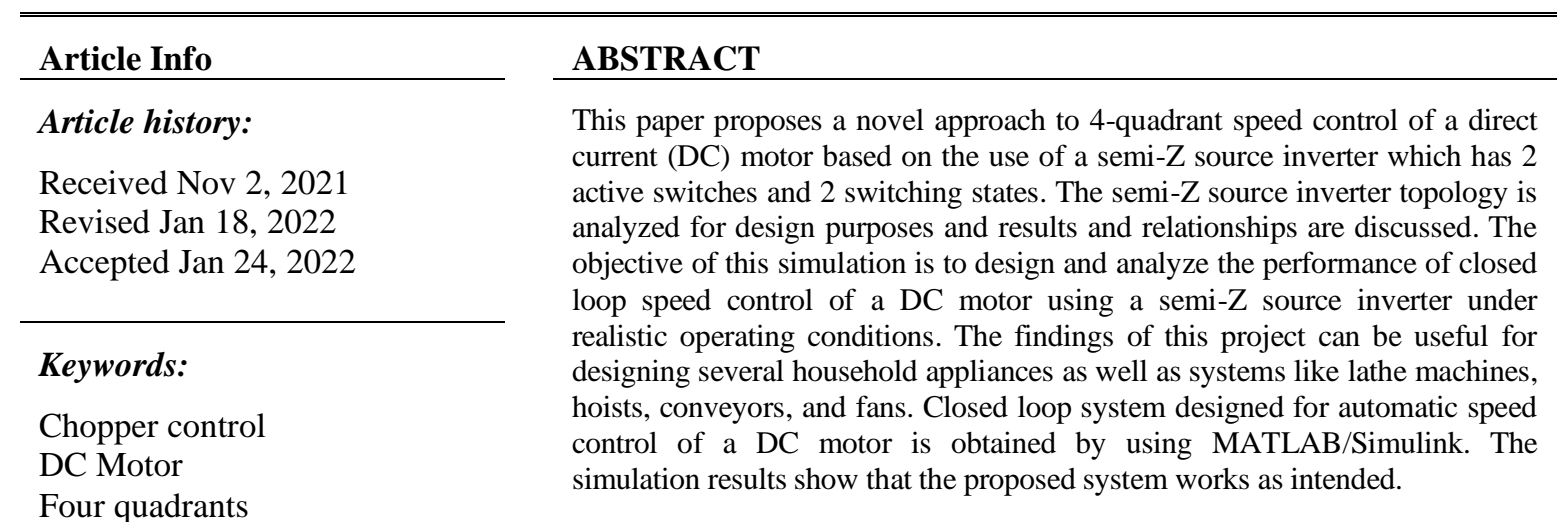

This is an open access article under the CC BY-SA license.

Semi Z-source

Speed control

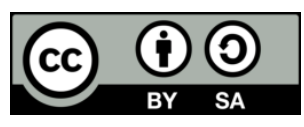

\section{Corresponding Author:}

Palanisamy Ramasamy

Department of Electrical and Electronics Engineering, SRM Institute of Science and Technology

Kattankulathur, Tamilnadu, 603203, India

Email: krspalani@gmail.com

\section{INTRODUCTION}

High performance motor drives are necessary parts of industrial applications. It has special characteristics such as good dynamic speed command tracking and load regulating response [1]-[4]. The methods of control are much simpler and less expensive than those of alternating current motors [5]. DC motors are widely used in telecommunication equipment power supplies, stair lifts, household appliances, certain low-cost automotive applications and as backup systems in industrial applications [6]-[8]. The present 4 quadrant control strategy for DC motors uses the class E chopper which has four active switches and requires a dead time between the two switching states [9], [10]. This paper proposes to replace the class E chopper with a semi-Z source inverter topology. The proposed topology forms a topological circuit consisting of three inductors, three capacitors, a resistor and two switches apart from power supply and back emf [11]-[13].

DC motor speed is directly proportional to armature voltage, by adjusting the armature voltage speed can be varied desirably [14]. Also, the DC motor is capable of running in both directions, which means four quadrant operation is possible [15], [16]. So, it is important to design a proper controller to control the speed of the DC motor [17]. However, due to lack of an appropriate mathematical model, a proper system using the alternative approach could not be designed with as much success as the original approach [18]-[20]. Nonetheless, a proper closed loop system using the originally proposed approach was successfully designed.

In order to bridge the gap in area of DC motor drive system this paper attempts the: i) dynamics of semi-Z source converter [21], ii) four quadrant operations of semi-Z-source inverter (ZSI) with resistor, 
inductor, battery load [22], iii) analysis of semi-Z source inverter, iv) designing of closed loop speed control of the system.

\section{PROPOSED SEMI-Z SOURCE CONVERTER}

The circuit shown in Figure 1 is the circuit taken up from the base paper and slightly modified. The original circuit uses a 2-pole Inductor and Capacitor filter on the output end. This is because the semi-Z source inverter was originally developed to be used for single phase Photovoltaic applications which require the output voltage ripple to be maintained within certain limits. This is dependent on the nature of the load.

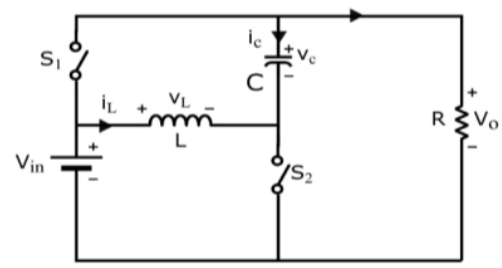

Figure 1. Semi-Z source inverter circuit

For a DC machine load, however, the output voltage ripple is not as critical. The machine has a back emf which ensures that the armature current ripple is maintained within acceptable limits even with a significantly high armature voltage ripple. Hence, the output side LC filter can be removed. The original circuit, thus, consists of 2 inductors and 2 capacitors and is a fourth order system. Omitting the LC filter reduces the order of the circuit from 4 to 2 . This makes the system easier to analyze and work with.

\section{ANALYSIS AND DESIGN}

\subsection{Notations and assumptions}

For any variable, the large signal value is the sum of its steady state and small signal value: i) lower case denotations represent large signal variables. For example, $d$ represents the large signal value of the duty cycle [23]-[25], ii) upper case denotations represent the steady state component of that variable. For example, $D$ represents the steady state component of the duty cycle, iii) lower case denotations with a hat on top represent the small signal component of that variable. For example, $\hat{d}$ represents the small signal component of the duty cycle, and iv) components with a dot on top represent time derivatives. For example, $\dot{d}$ represents the derivative of the large signal value of the duty cycle with respect to time, $v)\langle d\rangle$ represents the average value of $d$ over a switching period $T_{S}$. Assumptions made: i) derivatives of steady state value components is zero i.e, $\dot{\mathrm{D}}=0$, and ii) product of 2 or more small signal components is negligible i.e, $\widehat{d} \mathrm{x}$ $\widehat{v_{0}}=0$.

\subsection{Large signal model}

The large signal analysis for mode 1 , when switch $S_{1}$ is on as in Figure 2 (a):

for inductor, $v_{L}=\mathrm{L} i \dot{\mathrm{a}}_{L}$, for capacitor, $i_{C}=\mathrm{C} v_{C}$, and, $v_{o}=v_{I n}$. These equations can be arranged in state space form as shown.

$$
\begin{aligned}
& \dot{x}=A_{1} x+B_{1} u \\
& y=C_{1} x+E_{1} u
\end{aligned}
$$

Similarly, we get the following equations for switching mode 2, when S2 is on as in Figure 2 (b), for inductor, $v_{L}=\mathrm{Li} \Delta=v_{I n}$, for capacitor, $i_{C}=\mathrm{C} v_{C}=\frac{-v_{C}}{R}$, and $v_{o}=v_{C}$.

Arranging in state space form,

$$
\begin{aligned}
& \dot{x}=A_{2} x+B_{2} u \\
& y=C_{2} x+E_{2} u
\end{aligned}
$$

Average values are given as: 
$A=A_{1} d+A_{2}(1-d) ; B=B_{1} d+B_{2}(1-d)$;

$C=C_{1} d+C_{2}(1-d) ; E=E_{1} d+E_{2}(1-d)$

Thus, we get the final large signal state space model.

$$
\begin{aligned}
& \dot{x}=A_{1} x+B_{1} u \\
& y=C_{1} x+E_{1} u
\end{aligned}
$$

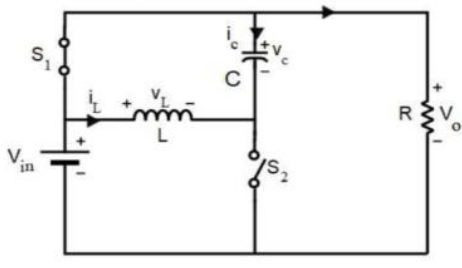

(a)

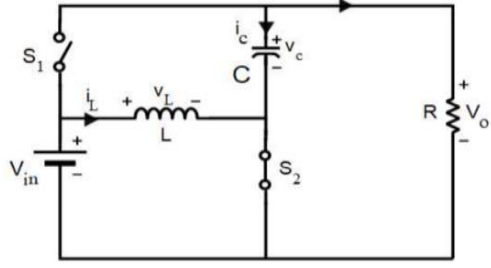

(b)

Figure 2. Switching modes in (a) $\mathrm{S}_{1} \mathrm{ON}$ and (b) $\mathrm{S}_{2} \mathrm{ON}$

\subsection{Steady state analysis}

The state space average model obtained is not linear. To get a linear system, we need to linearize the system around a steady state condition.

Thus, $\dot{x}=0=A_{1} x+B_{1} u$

The steady state current and voltage of $\mathrm{L}$ and $\mathrm{C}$ from (2) are given as:

$$
V_{C}=\frac{-V_{I n}(1-D)}{D} \& \quad I_{L}=\frac{-V_{C}(1-D)}{R D}
$$

from (1) we see that duty ratio [4] is, $\frac{V_{O}}{V_{I n}}=\frac{(2 D-1)}{D}$

\subsection{Small signal analysis}

Small signal perturbations are added to the large signal model, that is $+\hat{x}$, upon simplification we get,

$$
\dot{\hat{x}}=A \hat{x}+B \hat{u}+\left[\left(A_{1}-A_{2}\right) X+\left(B_{1}-B_{2}\right) U\right] \hat{d}
$$

The last 2 elements of the right-hand side can be combined to form a single element such that,

$$
\dot{\hat{x}}=A \hat{x}+\left[B ;\left(A_{1}-A_{2}\right) X+\left(B_{1}-B_{2}\right) U\right] \hat{u}_{\text {new }}
$$

Here,

If $\left[B ;\left(A_{1}-A_{2}\right) X+\left(B_{1}-B_{2}\right) U=B_{\text {new }}\right.$

Then, $\dot{\hat{x}}=A \hat{x}+B_{\text {new }} \hat{u}_{\text {new }}$

Similarly, adding perturbations in the output equation, that is $Y+\hat{y}$, upon simplification we get,

$$
\dot{\hat{y}}=C \hat{x}+E \hat{u}+\left[\left(C_{1}-C_{2}\right) X+\left(E_{1}-E_{2}\right) U\right] \hat{d}
$$

Finally, $\dot{\hat{y}}=C \hat{x}+E_{\text {new }} \hat{u}_{\text {new }}$

where, $\left[E ;\left(C_{1}-C_{2}\right) X+\left(E_{1}-E_{2}\right) U=E_{\text {new }}\right.$

Thus, we get the small signal model,

$$
\dot{\hat{x}}=A \hat{x}+B_{\text {new }} \hat{u}_{\text {new }}
$$

and, 


$$
\dot{\hat{y}}=C \hat{x}+E_{\text {new }} \hat{u}_{\text {new }}
$$

Applying Laplace transform to the small signal input in (3) and output in (4), and then substituting for $\hat{X}(s)$ we get,

$$
Y(s)=\left[C(s I-A)^{-1} B_{\text {new }}+E_{\text {new }}\right] \hat{u}_{\text {new }}(s)
$$

\section{SIMULATION STUDY}

The Semi-Z source inverter is designed considering the output which is intended. The main two components are the inductor and capacitor. Using the current and voltage ripple equations, the design equations of $\mathrm{L}$ and $\mathrm{C}$ are as follows:

$$
L=\frac{\operatorname{Vin}(1-D) T s}{2 \Delta i_{L}} \quad \& \quad C=\frac{\operatorname{Vin}(1-D)^{2} T_{S}}{2 \Delta v_{C} D R}
$$

Based on these equations, the value of inductance is calculated for $\Delta i_{L=} 2 \mathrm{~A}$ (allowing 2 amperes of ripple in inductor current) and the value of capacitance is calculated for $\Delta v_{C=} 0.125 \mathrm{~V}$ (allowing 0.125 volt of ripple in capacitor voltage), both at 0.38 duty cycle for continuous conduction. Duty cycle has been limited in range 0.38 to 0.75 for proper switching due to asymmetry at extreme points.

Based on the simulation profile data mentioned in the small signal transfer function of semi- $\mathrm{Z}$ source inverter is calculated at duty cycle $\mathrm{D}=0.5$, and is given as:

$$
\frac{\hat{v}_{o}(s)}{\hat{d}(s)}=\frac{-1.438 s+7188}{0.3125 s^{2}+3.125 s+3.125 e 04}
$$

From the transfer function it can be clearly seen that this semi-Z source inverter topology has a right half zero which results in a non-minimum phase system.

The speed is taken as feedback and is compared with reference speed, the generated error signal passes through the outer loop Proportional Integral controller which generates current proportional to reference voltage which is then compared further with feedback voltage in the inner loop. This generated error signal passes through the inner loop proportional integral derivative (PID) controller and generates a current proportional to duty ratio. Saturation block is used in the outer loop to limit voltage in range -150 to 150 and saturation block in inner loop is used to limit duty ratio in range 0.38 to 0.75 . Pulse width modulation (PWM) pattern is generated for the generated error signal by PWM block which is given to complementary switches $S_{1}$ and $S_{2}$. In this way this particular closed loop converter works.

According to the study by the authors, it is a non-minimum phase system having a right half zero, so it exhibits an undershoot at start. Due to this undershoot, error increases and while trying to correct this error, the controller increases duty cycle due to which it reaches peak negative value and then at this point it finally corrects itself, which is not acceptable. To overcome this, integral gain needs to be increased, which makes the response sluggish, which is acceptable over previous cases, which is shown in Figure 3.

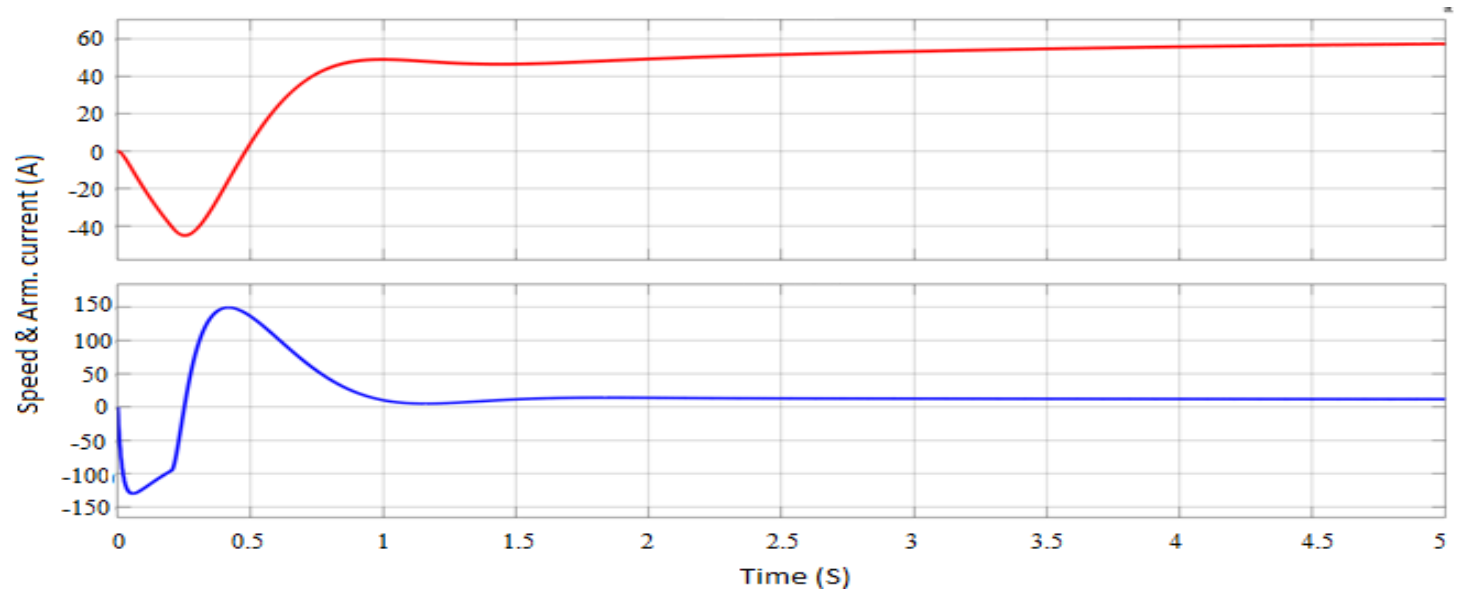

Figure 3. Closed loop systems with small integral controller exhibiting undershoot at start 


\subsection{Tuning of PID controller}

The classical controller design methods are used because physical systems are easier to implement and design as compared to one designed using modern control theory. These controllers are preferred in most industrial applications. For inner loop Ziegler Nichols sustained oscillations method is used, whereas for outer loop Chien, Hrones and Reswick Open loop tuning technique is used.

The controller transfer function is given as:

$$
\mathrm{G}_{\mathrm{c}}(\mathrm{s})=\mathrm{K}_{\mathrm{p}}\left(1+\frac{1}{\text { Tis }}+\mathrm{T}_{\mathrm{d}} \mathrm{s}\right)
$$

Both the methods are discussed.

\subsubsection{Ziegler Nichols closed loop tuning or sustained oscillations method}

This method of tuning is limited to tuning processes that cannot be applied on open loop systems. It allows us to find critical gain $\mathrm{K}_{\mathrm{Cr}}$ and critical period of oscillations $\mathrm{P}_{\mathrm{Cr}}$. A closed loop system with unity feedback is used in this method [15], [18]. The integral and derivative terms are made zero, with only proportional gain $(\mathrm{K})$. Initially $\mathrm{K}$ is set at low value and is gradually increased till the verge of instability, when the system produces sustained oscillations, it is shown in Figure 4. Gain at which the system produces sustained oscillation is called critical gain $\mathrm{K}_{\mathrm{Cr}}$ and the period of oscillation is $\mathrm{P}_{\mathrm{Cr}}$. Based on both the parameters PID controller gains are calculated by Table 1. Based on the performance of the system, values of critical gain and critical period are found as $\mathrm{K}_{\mathrm{Cr}}=2.0201$ and $\mathrm{P}_{\mathrm{Cr}}=0.016 \mathrm{~s}$ respectively, which is shown in Table 2. Sustained oscillation with period $\mathrm{P}_{\mathrm{Cr}}$ for gain $\mathrm{K}_{\mathrm{Cr}}$ is shown in Figure 5.

So based on the calculated values of $K_{P}, T_{i}, T_{d}$ controller transfer function is given as:

$$
\mathrm{G}_{\mathrm{c}}(\mathrm{s})=\left(1.212+\frac{151.512}{\mathrm{~s}}+424 \mathrm{e}-3 \mathrm{~s}\right)
$$

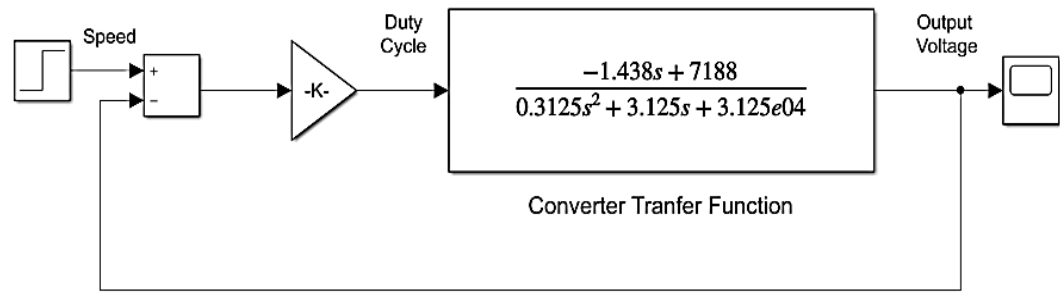

Figure 4. Closed loop inner voltage loop with proportional gain

Table 1. Ziegler Nichols closed loop calculation of

\begin{tabular}{cccc}
\multicolumn{4}{c}{$\mathrm{K}_{\mathrm{P}}, \mathrm{T}_{\mathrm{i}} \& \mathrm{~T}_{\mathrm{d}}$} \\
\hline Type of Controller & $\mathrm{K}_{\mathrm{P}}$ & $\mathrm{T}_{\mathrm{i}}$ & $\mathrm{T}_{\mathrm{d}}$ \\
\hline PID & $0.6 \mathrm{~K}_{\mathrm{Cr}}$ & $0.5 \mathrm{P}_{\mathrm{Cr}}$ & $0.125 \mathrm{P}_{\mathrm{Cr}}$ \\
\hline
\end{tabular}

Table 2. Calculated values of $K_{P}, T_{i} \& T_{d}$ for PID controller

\begin{tabular}{cccc}
\hline Type of Controller & $\mathrm{K}_{\mathrm{P}}$ & $\mathrm{T}_{\mathrm{i}}$ & $\mathrm{T}_{\mathrm{d}}$ \\
\hline PID & 1.212 & 0.008 & 0.002 \\
\hline
\end{tabular}

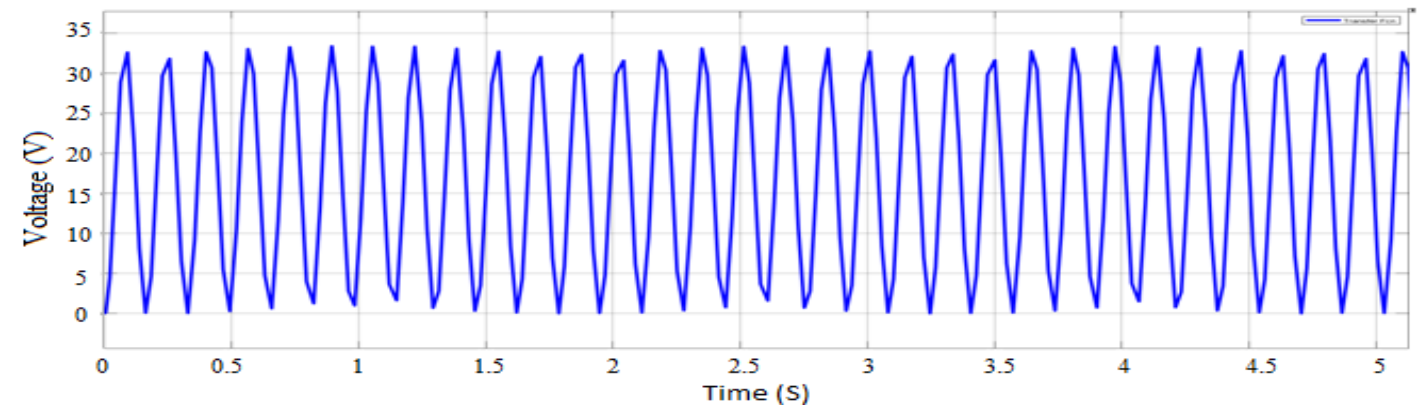

Figure 5. Sustained oscillation with period $\mathrm{P}_{\mathrm{Cr}}$ for gain $\mathrm{K}_{\mathrm{Cr}}$ 


\subsubsection{Chien, Hrones and Reswick (CHR) open loop tuning technique}

This is a modified version of Ziegler Nichols open loop process reaction method which provides a better way of selection of controllers for control applications. The process of finding controller gains for setpoint regulation with 0\% overshoot is summarized is shown in Figure 6.

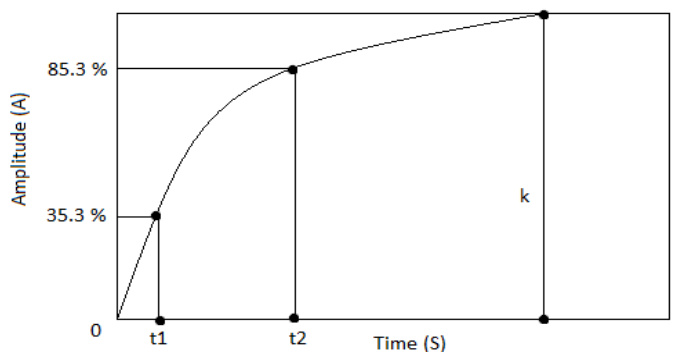

Figure 6. Step response of open loop process for CHR technique

$\mathrm{A}=1.3 \mathrm{t}_{1}-0.2 \mathrm{t}_{2}$

$\mathrm{B}=0.67\left(\mathrm{t}_{1}-\mathrm{t}_{2}\right)$

$\mathrm{K}=$ Output at steady state/input at steady state

Through the given standard formula, the PID controller gains can be calculated is shown in Table 3 . Based on the results $t_{1}$ and $t_{2}$ are found as $t_{1}=1.45 \mathrm{~s}$ and $t_{2}=16 \mathrm{~s}$ respectively, with these values, parameters for CHR method is shown in Table 4. And the Figure 7 shows Open loop simulation of outer speed loop for CHR technique. Step response of outer open loop is shown in Figure 8.

$\mathrm{A}=0.09$

$\mathrm{B}=8.375$

$\mathrm{K}=4.1$

So based on the calculated values of $K_{P}, T_{i}, T_{d}$ controller transfer function is given as:

$$
\mathrm{G}_{\mathrm{c}}(\mathrm{s})=\left(13.618+\frac{1.626}{\mathrm{~s}}+51.025 \mathrm{~s}\right)
$$

Table 3. CHR open loop calculation of $K_{P}, T_{i}, T_{d}$

\begin{tabular}{cccc}
\hline Controller & $\mathrm{K}_{\mathrm{P}}$ & $\mathrm{T}_{\mathrm{i}}$ & $\mathrm{T}_{\mathrm{d}}$ \\
\hline PID & $0.6 / \mathrm{K}$ & 2 & 0.5 \\
\hline
\end{tabular}

Table 4. Calculated values of $\mathrm{K}_{\mathrm{P}}, \mathrm{T}_{\mathrm{i}} \& \mathrm{~T}_{\mathrm{d}}$

\begin{tabular}{cccc}
\hline Controller & $\mathrm{K}_{\mathrm{P}}$ & $\mathrm{T}_{\mathrm{i}}$ & $\mathrm{T}_{\mathrm{d}}$ \\
\hline PID & 13.618 & 8.375 & 4.188 \\
\hline
\end{tabular}

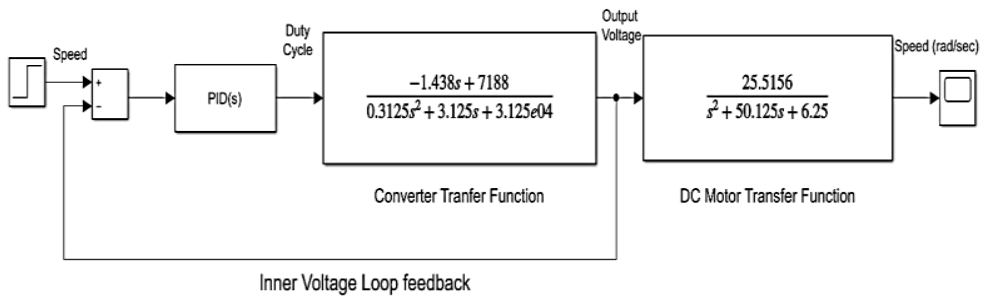

Figure 7. Open loop simulation of outer speed loop for CHR technique

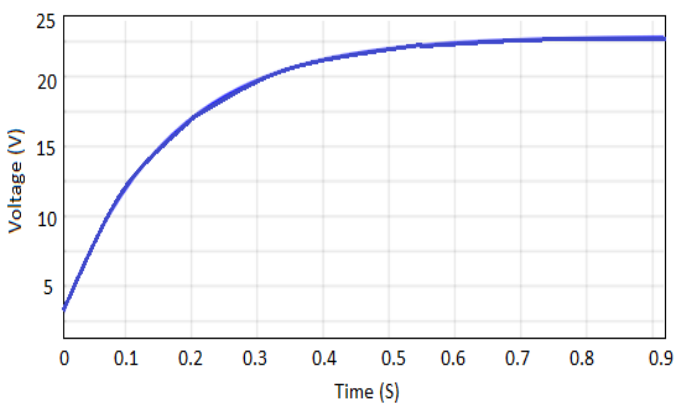

Figure 8. Step response of outer open loop 


\subsection{Tuning of PID controller - manual fine tuning}

The PID controllers tuned using classical control design methods involve design approximations, so the fine experimental on-site tuning is necessary to yield accurate results. The following are the controller gain values as obtained by manual tuning and the dynamics of change in controller gains, it is shown in Table 5.

The tuning of the inner loop is done first followed by the outer loop. The derivative controller is not used in the control system unless necessary, that is why most of the system employs PI controllers only. This is because when a sudden input is applied to the system, it compensates the output fast which in turn affects the controller to allow huge steady state errors in the long term. But in this system there is an undershoot in the negative direction of control, so derivative action needs to be taken into account to improve the transient response of the system. It should be kept in mind that increasing the value of $K_{D}$ beyond range slows down the response.

Therefore, based on all the analysis done so far, the final controller transfer functions are as follows:

$$
\begin{aligned}
& \text { PID Inner loop: } G_{c}(s)=1.2+\frac{160}{s}+(2.424 e-3 s) \\
& \text { PID Outer loop: } G_{c}(s)=20+\frac{1.6}{s}+(10 s)
\end{aligned}
$$

Table 5. Controller gains and system dynamics

\begin{tabular}{ccll}
\hline Gain & Value & \multicolumn{2}{c}{ Increase } \\
\hline & & \multicolumn{1}{c}{ Inner voltage loop } \\
$\mathrm{K}_{\mathrm{P}}$ & 1.2 & Little overshoot in current & No significant chance (slow response) \\
$\mathrm{K}_{\mathrm{I}}$ & 160 & Overshoot & Undershoot at start \\
$\mathrm{K}_{\mathrm{D}}$ & $2.4 \mathrm{e}-3$ & Slows down response & Undershoot at start \\
& & \multicolumn{1}{c}{ Outer speed loop } \\
$\mathrm{K}_{\mathrm{P}}$ & 20 & Overshoot in current & Sustained oscillations \\
$\mathrm{K}_{\mathrm{I}}$ & 1.6 & Overshoot in speed & Ripples in current \\
$\mathrm{K}_{\mathrm{D}}$ & 10 & Slow response & Undershoot for negative speeds \\
\hline
\end{tabular}

\section{RESULTS AND DISCUSSIONS}

\subsection{Open loop simulation results}

The following figures show the open loop simulation output done using MATLAB/Simulink for all the four quadrants with varying duty ratios. Initially the duty cycle is set to $70 \%$ at $\mathrm{t}=0 \mathrm{~s}$, then $50 \%$ at $\mathrm{t}=2.6 \mathrm{~s}$, then $40 \%$ at $t=5 \mathrm{~s}$ and finally $60 \%$ at $\mathrm{t}=7.6 \mathrm{~s}$. For this change the duty cycle speed changes from 0 to $62 \mathrm{rad} / \mathrm{s}$ (forward motoring), then from 62 to $-10 \mathrm{rad} / \mathrm{s}$ (forward braking), then from -10 to $-80 \mathrm{rad} / \mathrm{s}$ (reverse motoring) and finally from -80 to $32 \mathrm{rad} / \mathrm{s}$ (reverse braking) respectively, current is shown in Figure 9 and open loop-output voltage and it's mean is shown in Figure open loop-speed and armature 10.

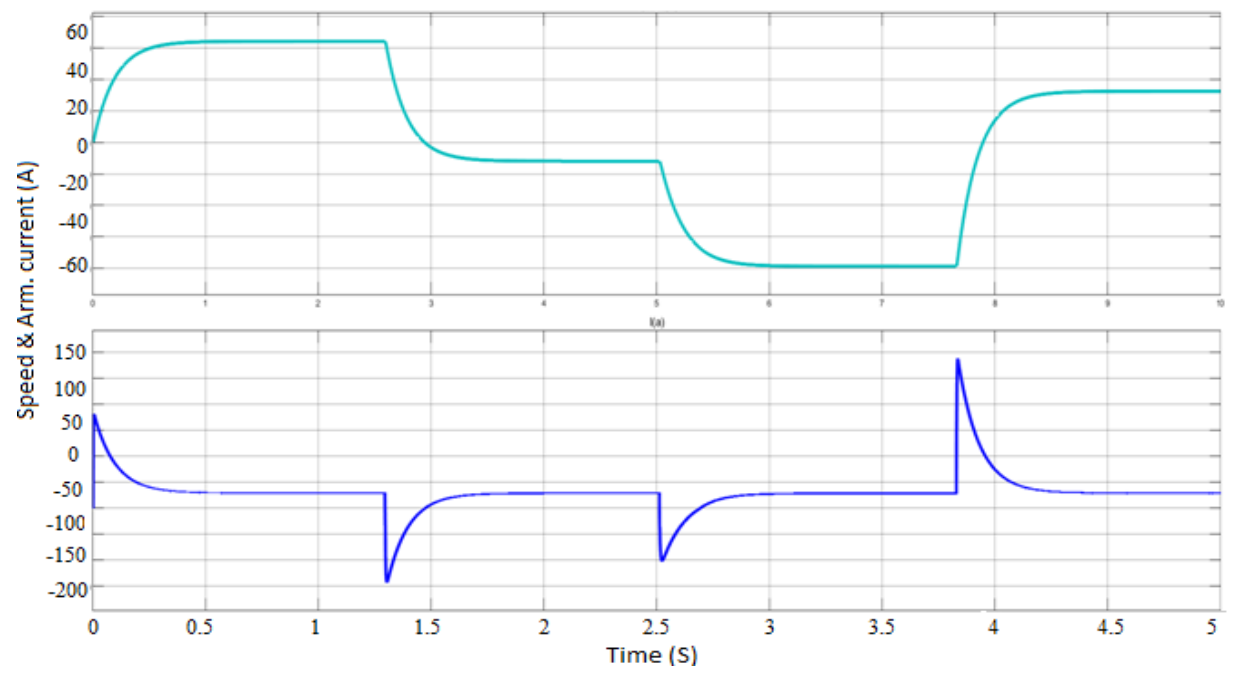

Figure 9. Open loop-speed and armature current 


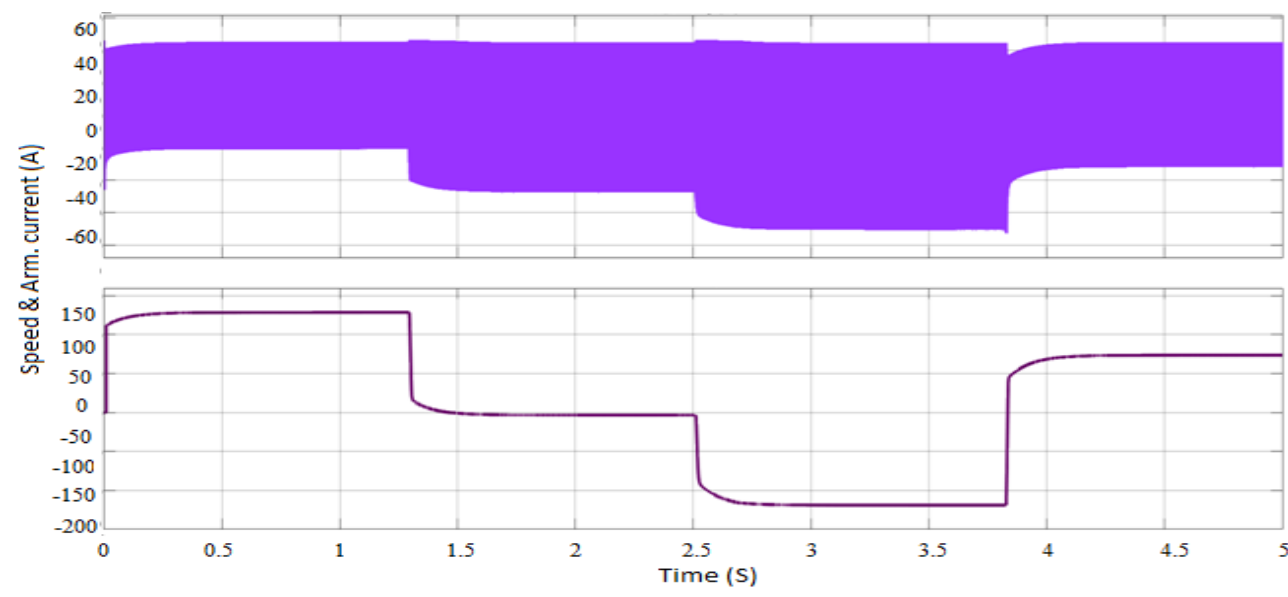

Figure 10. Open loop-output voltage and it's mean

\subsection{Closed loop simulation results}

\subsubsection{For varying speed reference}

The simulation results of the closed loop system for varying speed reference with PID controller is shown below. The speed reference is set to $50 \mathrm{rad} / \mathrm{s}$ at $\mathrm{t}=0 \mathrm{~s}, 30 \mathrm{rad} / \mathrm{s}$ at $\mathrm{t}=2.6 \mathrm{~s},-50 \mathrm{rad} / \mathrm{s}$ at $\mathrm{t}=5.1 \mathrm{~s}$ and finally to $-30 \mathrm{rad} / \mathrm{s}$ at $\mathrm{t}=7.5 \mathrm{~s}$. Figure 11 shows closed loop-speed and armature current and closed loop-output voltage and it's mean is shown in Figure 12.

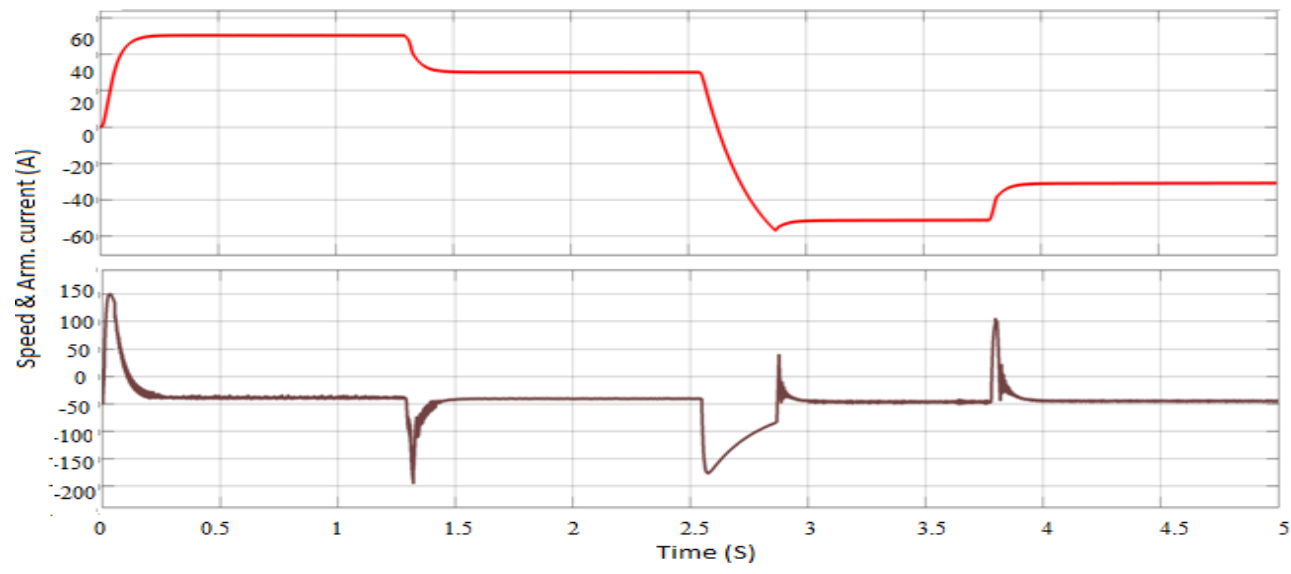

Figure 11. Closed loop-speed and armature current

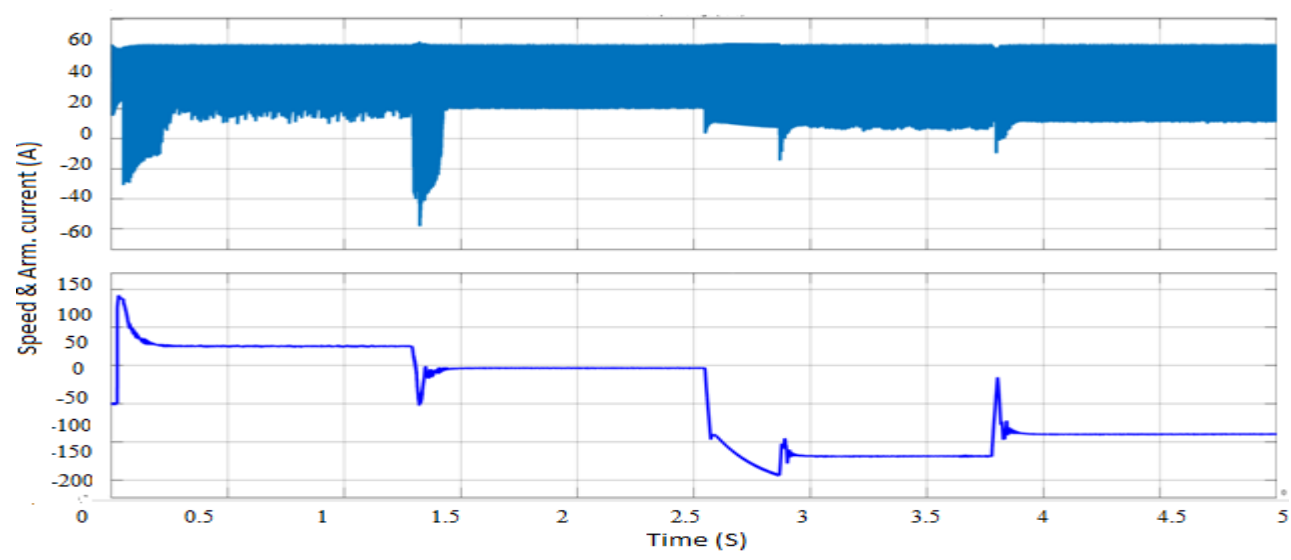

Figure 12. Closed loop-output voltage and it's mean 


\subsubsection{For varying load torques}

Shown below are the simulation results of the closed loop system for varying Load Torque with PID controller. The load Torque is varied from 0 to $10 \mathrm{~N} . \mathrm{m}$ at $\mathrm{t}=2.5 \mathrm{~s}$, from 10 to $50 \mathrm{~N} . \mathrm{m}$ at $\mathrm{t}=5 \mathrm{~s}$ and finally from 50 to 30 N.m at $t=7.5$ s. It can be seen that speed remains constant for different load torques. Closed loopspeed and armature current is shown in Figure 13 and closed loop-load and electromagnetic torque is shown in Figure 14.

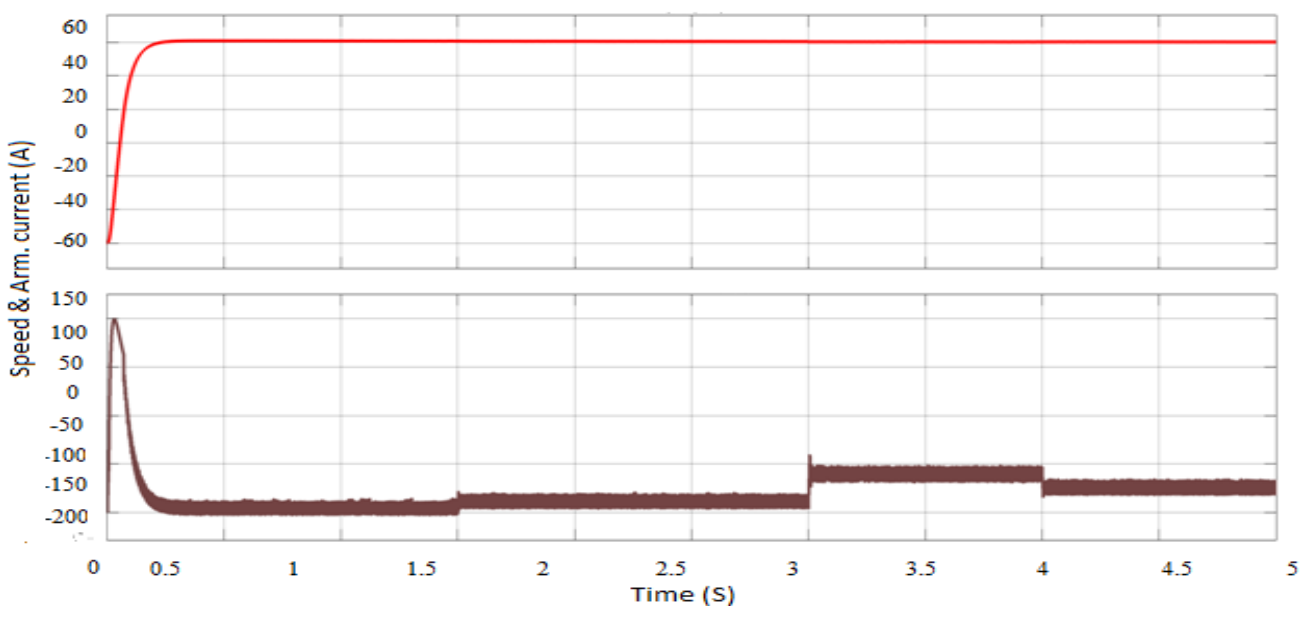

Figure 13. Closed loop-speed and armature current

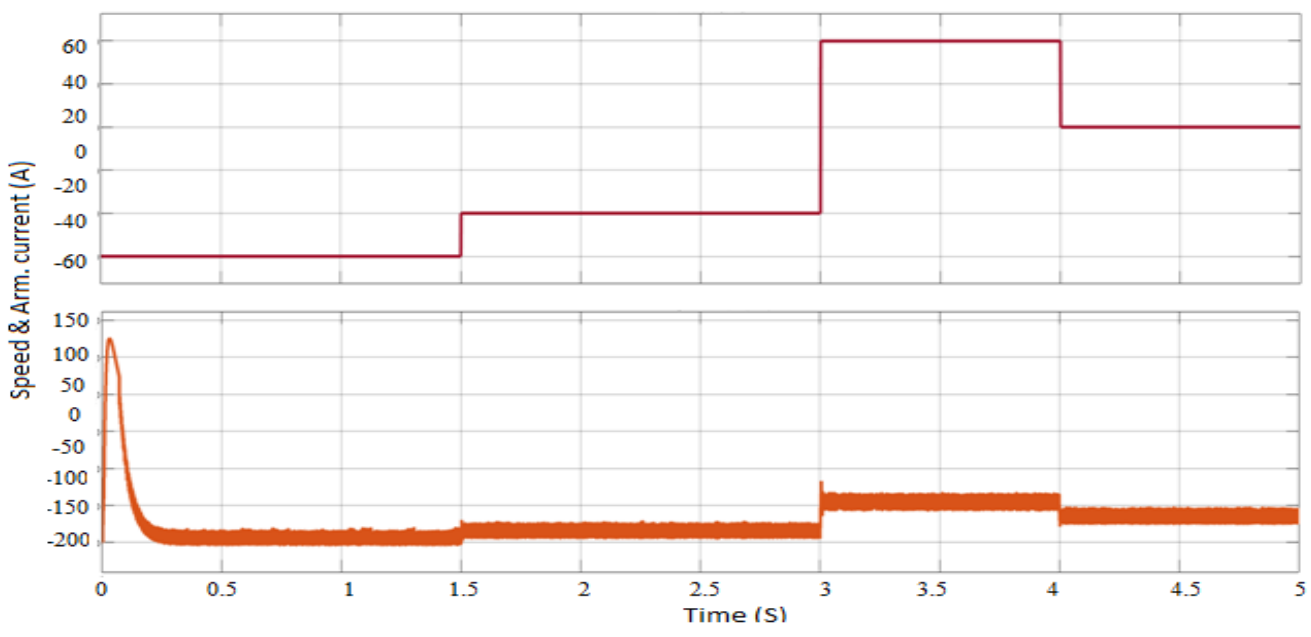

Figure 14. Closed loop-load and electromagnetic torque

\section{CONCLUSION}

In this paper a novel approach for the 4-quadrant speed control of a DC motor using a semi-Z source inverter was introduced. The steady state and small signal analysis of the semi-Z source inverter topology were discussed. The topology was first tested for open loop operation and it was found that it meets the requirements for the intended operation. The results of the analysis of the topology were used to design a closed loop system for output voltage control in both polarities. A DC machine load was connected to the output terminals and another closed loop control system was designed for speed control of the machine in all four quadrants. The designed system was simulated using MATLAB/Simulink and the results were discussed. The designed system successfully regulated the speed of the DC machine in all four quadrants and managed to maintain a constant speed even in varying torque conditions. Thus, it was found that the overall system works as intended. The designed system successfully meets all the performance requirements as well as the proposed objectives. 


\section{REFERENCES}

[1] V. S. Patil, S. Angadi, and A. B. Raju, "Four quadrant close loop speed control of DC motor," in 2016 International Conference on Circuits, Controls, Communications and Computing (I4C), 2016, pp. 1-6, doi: 10.1109/CIMCA.2016.8053305.

[2] D. Cao, S. Jiang, X. Yu, and F. Z. Peng, "Low-Cost Semi-Z-source Inverter for Single-Phase Photovoltaic Systems," IEEE Transactions on Power Electronics, vol. 26, no. 12, pp. 3514-3523, Dec. 2011, doi: 10.1109/TPEL.2011.2148728.

[3] R. latha, C. Bharatiraja, R. Palanisamy, sudeepbanerji, and S. S. Dash, "Hysteresis Current Controller based Transformerless Split Inductor-NPC-MLI for Grid Connected PV- System," Procedia Engineering, vol. 64, pp. 224-233, 2013, doi: 10.1016/j.proeng.2013.09.094.

[4] A. A. Hassan, N. K. Al-Shamaa, and K. K. Abdalla, "Comparative Study for DC Motor Speed Control Using PID Controller," International Journal of Engineering and Technology, vol. 9, no. 6, pp. 4181-4192, Dec. 2017, doi: 10.21817/ijet/2017/v9i6/170906069.

[5] A. Mostaan and M. Soltani, "A family of four quadrant DC/DC converters with reduced number of components," in 2015 IEEE International Telecommunications Energy Conference (INTELEC), 2015, pp. 1-6, doi: 10.1109/INTLEC.2015.7572307.

[6] S. K. Suman and V. K. Giri, "Speed control of DC motor using optimization techniques based PID Controller," in 2016 IEEE International Conference on Engineering and Technology (ICETECH), 2016, pp. 581-587, doi: 10.1109/ICETECH.2016.7569318.

[7] L. Karunakar, C. N. Naveena, P. Sowjanya, and K. S. Lakshmi, "Power Factor Correction Using Step-Up Chopper Fed to a DC Motor Drive," International Journal for Modern Trends in Science and Technology, vol. 3, no. 2 (special issue), pp. $26-30,2017$.

[8] D. A. Barkas, G. C. Ioannidis, C. S. Psomopoulos, S. D. Kaminaris, and G. A. Vokas, "Brushed DC Motor Drives for Industrial and Automobile Applications with Emphasis on Control Techniques: A Comprehensive Review," Electronics, vol. 9, no. 6, p. 887, May 2020, doi: 10.3390/electronics9060887.

[9] R. Palanisamy and K. Vijayakumar, "SVPWM for 3-phase 3-level Neutral Point Clamped Inverter Fed Induction Motor Control," Indonesian Journal of Electrical Engineering and Computer Science, vol. 9, no. 3, p. 703, Mar. 2018, doi: 10.11591/ijeecs.v9.i3.pp703-710.

[10] A. A. A. Emhemed and R. Bin Mamat, "Modelling and Simulation for Industrial DC Motor Using Intelligent Control," Procedia Engineering, vol. 41, pp. 420-425, 2012, doi: 10.1016/j.proeng.2012.07.193.

[11] M. George, "Speed Control of Separately Excited DC Motor," American Journal of Applied Sciences, vol. 5, no. 3, pp. 227-233, Mar. 2008, doi: 10.3844/ajassp.2008.227.233.

[12] A. Thakur, "Improvement of Back EMF \&amp; Minimization of Torque Ripple of BLDC Motor," SMART MOVES JOURNAL IJOSCIENCE, vol. 5, no. 8, pp. 1-7, Aug. 2019, doi: 10.24113/ijoscience.v5i8.220.

[13] K. Jayaswal and D. K. Palwalia, "Performance Analysis of Non-Isolated DC-DC Buck Converter Using Resonant Approach," Engineering, Technology \& Applied Science Research, vol. 8, no. 5, pp. 3350-3354, Oct. 2018, doi: 10.48084/etasr.2242

[14] A. M. De Paor and M. O’Malley, "Controllers of Ziegler-Nichols type for unstable process with time delay," International Journal of Control, vol. 49, no. 4, pp. 1273-1284, Apr. 1989, doi: 10.1080/00207178908559705.

[15] X. Li, X. Ruan, Q. Jin, M. Sha, and C. K. Tse, "Approximate Discrete-Time Modeling of DC-DC Converters With Consideration of the Effects of Pulse Width Modulation," IEEE Transactions on Power Electronics, vol. 33, no. 8, pp. 7071-7082, Aug. 2018, doi: 10.1109/TPEL.2017.2752419.

[16] D. Puangdownreong, A. Nawikavatan, and C. Thammarat, "Optimal Design of I-PD Controller for DC Motor Speed Control System by Cuckoo Search," Procedia Computer Science, vol. 86, pp. 83-86, 2016, doi: 10.1016/j.procs.2016.05.021.

[17] Seung Cheol, Shin Chool, Kyu Han, Yong Sung, and Jae Hyung, "A design of I-PD controller using CDM," in 2007 International Conference on Control, Automation and Systems, 2007, pp. 477-480, doi: 10.1109/ICCAS.2007.4406955.

[18] R. Palanisamy, K. Vijayakumar, A. Bagchi, V. Gupta, and S. Sinha, "Implementation of Coupled Inductor Based 7-level Inverter with Reduced Switches," International Journal of Power Electronics and Drive Systems (IJPEDS), vol. 8, no. 3, p. 1294, Sep. 2017, doi: 10.11591/ijpeds.v8.i3.pp1294-1302.

[19] V. Rajinikanth and K. Latha, "I-PD Controller Tuning for Unstable System Using Bacterial Foraging Algorithm: A Study Based on Various Error Criterion," Applied Computational Intelligence and Soft Computing, vol. 2012, pp. 1-10, 2012, doi: $10.1155 / 2012 / 329389$

[20] X.-S. Yang and Suash Deb, "Cuckoo Search via Lévy flights," in 2009 World Congress on Nature \& Biologically Inspired Computing (NaBIC), 2009, pp. 210-214, doi: 10.1109/NABIC.2009.5393690.

[21] S. N. Singh and D. R. Kohli, "Performance Determination of a Chopper-Controlled Separately Excited DC Motor," IEEE Transactions on Industrial Electronics, vol. IE-31, no. 1, pp. 37-42, Feb. 1984, doi: 10.1109/TIE.1984.350018

[22] K. Selvakumar, R. Palanisamy, K. Vijayakumar, D. Karthikeyan, D. Selvabharathi, and V. Kubendran, "Hysteresis Control 3Level SI-NPC Inverter with Wind Energy System," International Journal of Power Electronics and Drive Systems (IJPEDS), vol. 8, no. 4, p. 1764, Dec. 2017, doi: 10.11591/ijpeds.v8.i4.pp1764-1770.

[23] K. B. Naik, G. K. Dubey, and V. k. Jain, "Steady State and Dynamic Response Analysis of a Chopper Controlled DC Separately Excited Motor," IEEE Transactions on Power Apparatus and Systems, vol. PAS-104, no. 7, pp. 1774-1782, Jul. 1985, doi: 10.1109/TPAS.1985.319212.

[24] B. Mellitt and M. H. Rashid, "Analysis of d.c. chopper circuits by computer-based piecewise-linear technique," Proceedings of the Institution of Electrical Engineers, vol. 121, no. 3, p. 173, 1974, doi: 10.1049/piee.1974.0031.

[25] B. W. Williams, "Complete State-Space Digital Computer Simulation of Chopper-Fed DC Motors," IEEE Transactions on Industrial Electronics and Control Instrumentation, vol. IECI-25, no. 3, pp. 255-260, Aug. 1978, doi: 10.1109/TIECI.1978.351561. 


\section{BIOGRAPHIES OF AUTHORS}
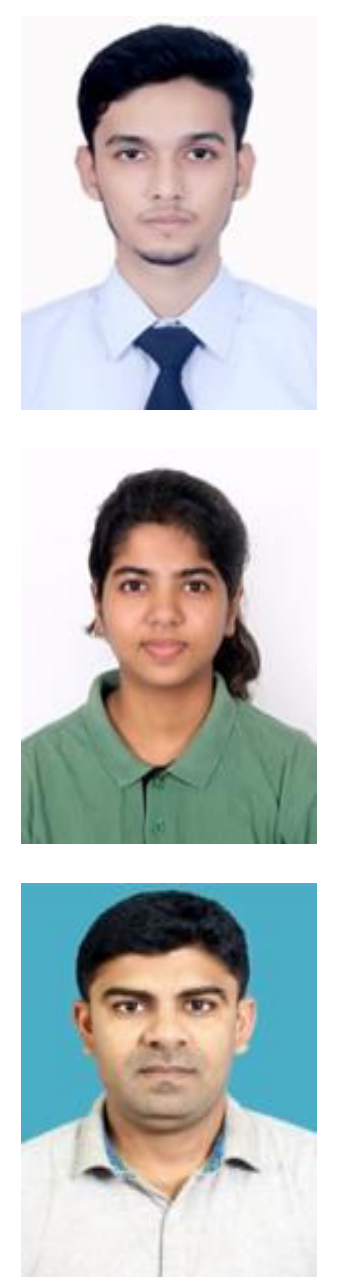

Waseah Anjum (D) 8d SC P received his Bachelor of Technology degree in Electrical and Electronics Engineering from SRM Institute of Science and Technology, Chennai, India in 2021. He is currently working as a freelance project manager for a startup company currently not public. His research interests include power electronics, electrical machines electromobility and renewable energy systems. He can be contacted at email: waseah1990@gmai.com.

Sudeekshya Panda (D) SI SC P received his Bachelor of Technology degree in Electrical and Electronics Engineering from SRM Institute of Science and Technology, Chennai, India in 2021. He is currently working as a freelance project manager for a startup company currently not public. His research interests include power electronics, electrical machines electromobility and renewable energy systems. She can be contacted at email: sudeekshyapanda15@gmail.com.

Palanisamy Ramasamy (iD) $8 \mathrm{SC}$ P received the B.E. degree in electrical and electronics engineering from Anna University, India, in 2011, and the M.Tech. degree in power electronics and drives and the Ph.D. degree in power electronics from the SRM Institute of Science and Technology, Chennai, India, in 2013 and 2019, respectively. He is currently working as an Assistant Professor with the Department of Electrical Engineering, SRM Institute of Science and Technology. He has published more than 95 international and national journals. His research interests include power electronics multilevel inverters, various PWM techniques for power converters, FACTS controllers, and grid connected photovoltaic systems. He can be contacted at email: palanis@ srmist.edu.in. 